\title{
Coulisses
}

Revue de théâtre

2 | Automne 1990

Spécial Festival des idées : Besançon ville ouverte aux jeunes

\section{La Valse des Papillons. 1, 2, 3 Clown}

Atelier Théâtre des Tilleuls

\section{Rédaction}

\section{CpenEdition}

\section{Journals}

Édition électronique

URL : http://journals.openedition.org/coulisses/1593

DOI : $10.4000 /$ coulisses. 1593

ISSN : 2546-9460

\section{Éditeur}

Presses universitaires de Franche-Comté

\section{Édition imprimée}

Date de publication : 1 novembre 1990

Pagination : $\mathrm{np}$

ISSN : 1150-594X

\section{Référence électronique}

Rédaction, «La Valse des Papillons. 1, 2, 3 Clown », Coulisses [En ligne], 2 | Automne 1990, mis en ligne le 04 juillet 2017, consulté le 23 octobre 2019. URL : http://journals.openedition.org/coulisses/1593 ; DOI : 10.4000/coulisses. 1593

Ce document a été généré automatiquement le 23 octobre 2019

Coulisses 


\title{
La Valse des Papillons. 1, 2, 3 Clown
}

\author{
Atelier Théâtre des Tilleuls
}

\section{Rédaction}

1 Jeudi 14 Juin, le public du Petit-Kursaal a saturé par une véritable ovation, la performance des 14 acteurs handicapés mentaux de l'atelier-théâtre des tilleuls.

2 Pour sa deuxième participation à BVOJ, l'atelier des Tilleuls a allié danse, musique et théâtre, avec son spectacle 1, 2, 3 Clown, précédé d'un court tableau d'expression corporelle et de danse intitulé « la valse des papillons ». Le prologue dansé sur un air de valse viennoise évoque les différentes étapes de la vie des papillons. Le jeu des tissus amples et colorés, des costumes des comédiens met en valeur chaque danseur. Véronique Sélène, la chorégraphe, assure par sa présence la cohésion de tous les "papillons » parfois bien embarrassés de leurs propres ailes. Ce tableau haut en couleur n'est qu'une première partie, dont la suite est 1, 2, 3 Clown.

3 Dans un décor dépouillé (rideau fond de scène) Véronique Sélène s'installe côté cour à l'avant-scène sur une chaise et nous fait assister à la générale de son spectacle, commentant entre chaque sketch la performance des acteurs, les corrigeant si nécessaire ou accusant l'accessoiriste de ne pas faire son travail. Cette "pseudo générale » met en scène des personnages très divers dans des situations toutes plus cocasses les unes que les autres : pareille à un "disque rayé », une chanteuse rivalisant de narcissisme avec la Castafiore, entonne un sempiternel «Ah! je suis belle ! J'ai une belle robe ! » en s'accompagnant à la mandoline ; une maîtresse d'école complètement débordée dans sa classe mise sens dessus dessous par des élèves joyeux drilles et chahuteurs; dans une salle d'audience "le meilleur avocat du monde » au plaidoyer désopilant face à un procureur irascible, menaçant de faire « évacuer la salle » à chaque salve d'applaudissements du public. Une avalanche de gags, un rythme très enlevé, une étude de caractères bien fouillée, le tout complété par la malice naïve du jeu et des propos des comédiens, fait de 1, 2, 3 Clown un spectacle différent.

4 Souhaitons donc à l'atelier Théâtre des Tilleuls qui n'a que 3 ans de réaliser son projet : participer en 1991 au Festival des Artistes Handicapés Mentaux de Figeac. 


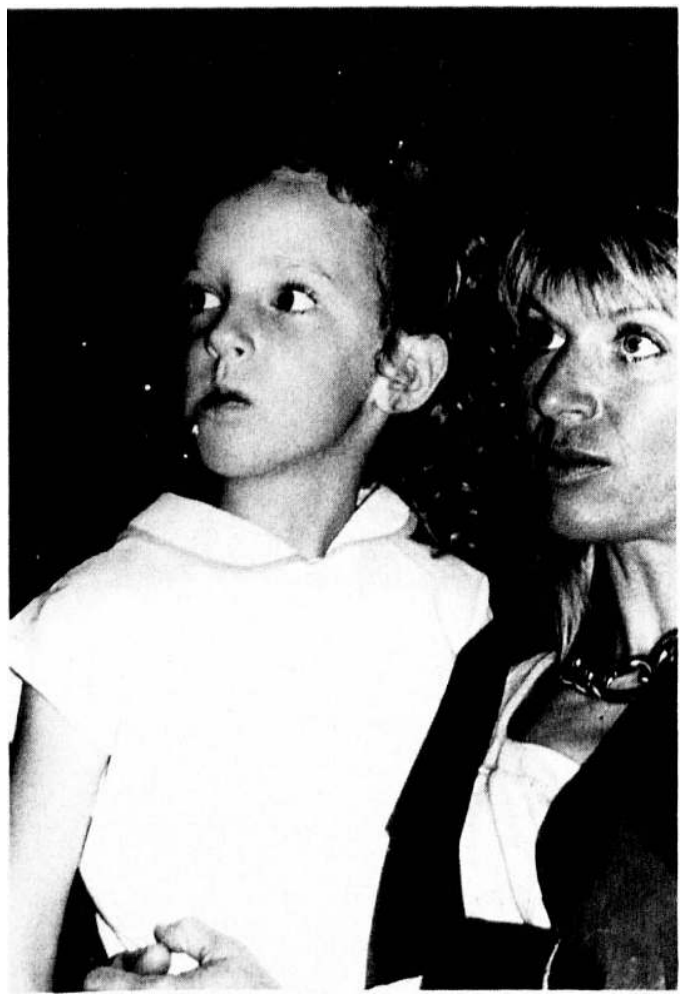

(c) Collectif Photo BVOJ 90. 